time of the accident the shoulder joint or the muscles of the shoulder region may be injured, and as full movements of the joint cannot be maintained until the fracture is united limitation of movement may become obvious when all fixation has been removed. The limitation may be reduced by the patient's own efforts during treatment, but massage and exercises may be needed at a later date.

A much more serious state of rigidity is encountered in those patients; especially adults, in whom the hand and fingers have been kept at rest during the course of treatment. Massage and voluntary exercises help to diminish the rigidity, but as a rule a considerable disability is left if the possibility is forgotten.

Non-union.-Non-union of a fracture of the clavicle is a comparatively rare complication, especially when the fracture is simple. It may occur in spite of correct and efficient treatment, but is usually seen only when treatment has been neglected or when a portion of the bone has been removed in a compound fracture. As a result of non-union the patient usually complains of aching and a feeling of clicking when the arm is used. There is usually little or no tenderness over the fracture, but the movements of the fractured surfaces on each other are disabling.

\section{Treatment of Non-union}

On occasion, union of the fractured bone can be obtained by continuing the fixation for a longer period. If the fracture is comparatively recent a further period of fixation of four to six weeks may be sufficient to produce a sound, painless union. When non-union has been present for a considerable period even prolonged fixation is usually unsuccessful in producing union, and operative interference is advisable.

Bone Grafting.-In attempting to produce bony union a bone graft is applied to the site of fracture. An inlay graft is placed in a deep slot cut on the antero-inferior aspect of the clavicle and reduction maintained as in a fresh fracture of the bone. Because of the difficulty of obtaining complete fixation of the fracture the bone-grafting operation may not be successful, and if the operation has failed on the first occasion the prognosis is much worse if a further attempt is made.

Partial or Complete Removal of the Clavicle.-If bone grafting has failed and the patient still complains of pain and disability a considerable improvement in the condition may be effected by the removal of a large section of the clavicle from either side of the fracture. As a result of this the painful clicking of the fractured surfaces is eliminated, and though the shoulder tends to fall forward to a slight degree the usefulness of the limb is increased. Because of the possibility of the re-formation of the clavicle which has been removed it may be advisable on occasion to remove the whole of the bone, which, though apparently a radical procedure, does little to reduce the strength and usefulness of the affected limb.

The Ministry of Health has notified hospital boards and committees that it will not set up any central machinery for dealing with redundant, worn-out, or obsolete equipment in hospitals. Boards and committees should dispose of such equipment as before. Serviceable items of equipment which become redundant in any hospital should be transferred to another hospital where they can be used. No cash adjustment should be made for the transfer, but it should be recorded. Hospitals holding equipment issued on loan during the war under the Emergency Hospital Scheme should use it where possible. Schedules of this equipment should be prepared and sent to the Ministry of Health, Supplies Division 1, Whitehall, London.

\section{SURGICAL TRAVELS IN COLOMBIA}

BY

\author{
RONALD W. RAVEN, O.B.E., F.R.C.S.
}

Honorary Professor, National University of Colombia; Surgeon to the Westminster Hospital (Gordon Hospital); Surgeon to the Royal Cancer Hospital

Surgical travels in other lands are full of interest, and are valuable for the development of understanding between the countries involved. Our country always welcomes the surgeons of other lands to her surgical centres, and many avail themselves of the facilities provided. Others find it impossible to make the journey, but they can be reached and helped when British surgeons undertake such a mission as is described in this paper. The National University of Colombia extended an invitation to Dr. Lawrence $\mathrm{H}$. Morris and myself to visit Bogotá in order to deliver a course of lectures and perform surgical operations. This invitation was accepted, and we left England on April 26, 1949. As this is the first occasion such a visit has been made, it is felt that a record of it might be of interest.

\section{Historical Background of Colombia}

Colombia is the only country in the New World which bears the name of the discoverer, Christopher Columbus. The exploration of this region was carried out by his companions and contemporaries. and resulted in the foundation there of Santa Marta in 1525 and Cartagena in 1533. These ports developed into two of the most important centres of this vast continent and became the scene of many struggles and sieges in bygone days. In some of these expeditions Sir Francis Drake was actively engaged. The last great attack which Cartagena suffered in the colonial age was in 1741, when Sir Edward Vernon arrived at the head of the greatest army ever to reach the coasts of the Caribbean Sea.

Colombia was the cradle of the great Chibcha and Kimbaya Indian civilizations, which fell before the Spaniards. Santa $\mathrm{Fe}$ de Bogotá was founded by Jiménez de Quesada after a heroic expedition, and the future capital of the country came into being. Its history is bound up with the revolt of the Comuneros and the beginnings of Colombian science under Mutis and Caldas. Finally there came the great revolutionary movement organized by Bolivar, Nariño, and Santander, which transformed the country and ended in its independence being established. The Colombians have never forgotten the help they received from the British soldiers in their fight for freedom.

\section{Geographical Facts}

Colombia extends over an area of nearly half a million square miles of land in the north-western region of South America. It is the only country in this continent to face two great oceans, since its western seaboard opens on the Pacific Ocean while its northern coastline looks out on that portion of the Atlantic Ocean which forms the Caribbean Sea.

The outstanding feature of the country is the gigantic mountain ranges of the Andes, which rise in the Caribbean region and continue southward across the continent. This great mountain system spreads out into three main ranges, united in the south-west and opening towards the north. Thus on the left is the Western Cordillera of Chocó, in the middle the Central Cordillera of Quindio, and on the right the Eastern Cordillera of Sumapaz. Scattered among these mountain ranges are high tablelands where the population is denser, especially in the eastern region. To the east and south-west of the Eastern Cordillera is an immense plain traversed by the great rivers Caquetá and Vichada, which empty respectively into the Amazon and the Orinoco.

The country lies entirely within the Tropics, but the climatic conditions vary greatly. The line of the Equator traverses its southern part, but when the rivers, forests, and lowlands are left behind, temperate valleys and plateaux are reached where there is perpetual springtime with orchards and flowers in full bloom; and rising high above the plateaux are the mountains. 


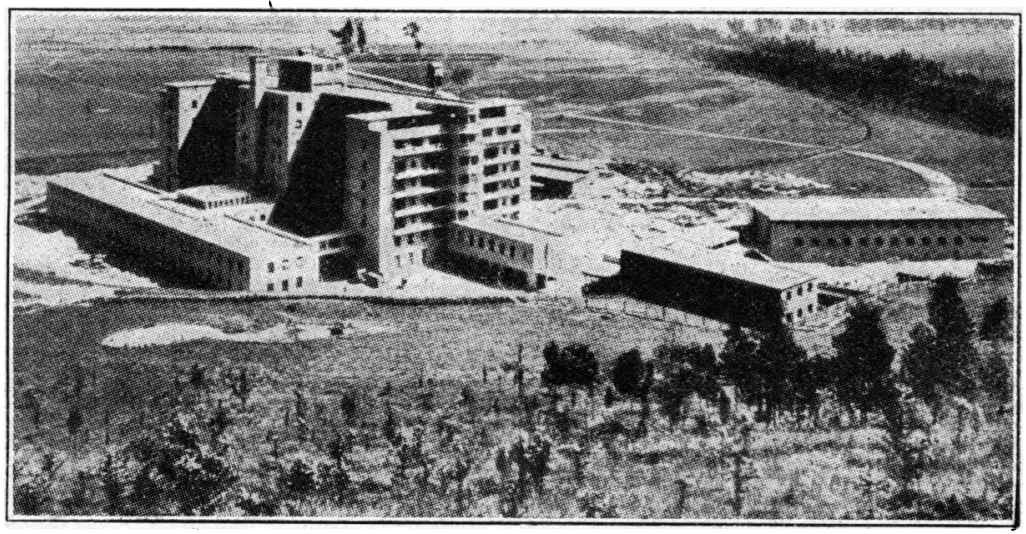

Fig. 1.-The San Carlos Hospital, Bogotá.

covered always with snow. The dry and wet seasons alternate at intervals of three months, starting with a dry period from December to February.

Colombia is a land of contrasts, and these are most striking when seen from an airplane. The landscape is always changing, revealing interwoven greens, browns, and blues. The huge mountain ranges, their jagged summits rising up against the sky, the rivers winding in the valleys, and the numerous primeval forests scattered throughout the country are an impressive sight.

The flora is abundant and diverse, and botanists affirm that more than fifteen thousand specimens have been described. Many of the wild plants, like the chupahuevo and matarroton, are said to possess medicinal properties; and parasitic plants abound, notably the orchids which grow in rich profusion on the trunks of trees.

On the plains and in the valleys immense herds of cattle graze, and sheep and pigs are being reared on an increasing scale. Also, horses are imported from England to improve the local breeds. In the jungle there are various wild animals, including jaguars, tapirs, boars, deer, pumas, foxes, and bears, in addition to numerous species of monkeys and squirrels. The rivers contain the crocodile, the gliding eel, small salmon, the bagre, and the captain fish. Amongst the marshes and lakes are found waterfowl, heron, and wild duck, and on the moors quail, partridge, and pigeon. It is possible to see on the mountain crags a hawk or the rare condor. Many varieties of butterflies exist here, and numerous kinds of parrots, macaws, and parakeets.

There is a very interesting area known as the Macarena Hills, which is infested with monkeys and where yellow fever is rife. Consequently it has never been explored by man until recently. The control of yellow fever by inoculation has now made this possible. A research centre has been established with its headquarters in Villavicencia, and we had the opportunity of meeting and talking with the director of this work. A number of interesting biological investigations are being carried out, and it is hoped to extend these researches in the future. This appears to be a fruitful field for capable trained investigators.

\section{The Travel Itinerary}

We went to New York by sea, and, after spending one night in that city, travelled by air to our destination in Colombia. It was a grand flight over Miami in Florida, Cuba, and Jamaica: the beauty of the islands in the Caribbean Sea is most impressive. We reached Colombia at Barranquilla, a fine international port which is linked by the Magdalene River with the heart of the country. Here we received a warm welcome before proceeding by air to Bogotá, the capital city, where our main work was to be done. We were met by a deputation which included the Minister of Hygiene, the Director of the National Radium Institute, the representatives of the British Council, and a number of professors and doctors.

Bogotá is situated on the great plain-the Sabana de Bogotá-at a height of 8,500 feet above sea-level. It was established over 400 years ago, and is divided into old and modern sections, the former of which has a distinctly Spanish atmosphere, with narrow winding streets, big balconies on large colonial houses with gay patios, and peaceful little squares. Possessing a population of more than 600,000 persons, it is the centre of the political and cultural life of the country. The National University of Colombia occupies an area of 400 acres and has a large faculty of medicine. We spent four weeks working in Bogotá, and then left by air for Medellin, the capital of the rich department of Antioquia. This city was founded in 1674, and is recognized as one of the greatest industrial centres of Colombia. We worked in the University of Antioquia for three days and then proceeded by air to Cartagena.

Cartagena is a historic city of great grandeur situated on one of the beautiful bays of the Caribbean Sea. It is an important intellectual centre, with its university, the Academy of History, and the Naval School of the Colombian Navy. We spent a short period of two and a half days at work in the university. From Cartagena we went by air to the U.S.A. and attended the Joint Meeting of the American Proctologic Association and the Proctological Section of the Royal Society of Medicine, which was held in Columbus, Ohio. From Columbus we flew to New York and returned to England by sea.

\section{Surgical Work in Bogotá}

At the National University a large number of medical students are being trained. The curriculum extends over a period of six years, and after qualification resident appointments in the hospitals are available. Facilities are also provided for those who desire to make a study of special branches of medicine and surgery; these graduates often spend a period in the specialized clinics in England and the U.S.A. Many expressed a wish to come to England for this purpose.

The teaching hospitals vary greatly in size, the largest containing 1,200 beds. The treatment of cancer patients is mostly carried out in the National Radium Institute- a school of the University-whose director is a professor of surgery. This very active surgical centre also possesses a radiological department divided into therapeutic and diagnostic sections, a pathological department, and a statistical department. A large number of undergraduates attend the practice of this hospital.

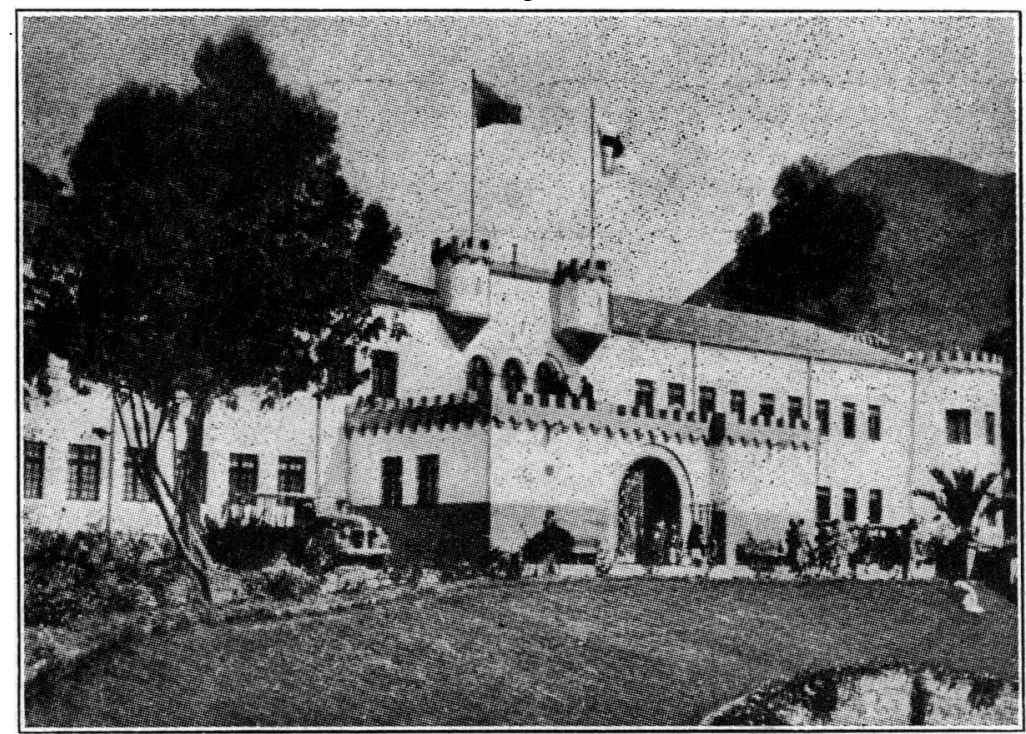

F10. 2.-1 he Milıtary Hospital, Bogotá. 
An important addition to the hospitals in Bogota is the new San Carlos Hospital (Fig. 1) for the medical and surgical treatment of tuberculosis. It embraces the most recent developments in hospital design, and is equipped with every modern device, including its own laundry. From its lay-out, especially in connexion with the wards and operation theatres, this hospital may be considered a model of its kind.

In addition to the civil hospitals there is the military hospital (Fig. 2)-a well-equipped institution beautifully situated amongst the hills.

The staffs of the hospitals are extremely keen and capable. A number of surgeons are engaged in various specialties, which include thoracic, gynaecological, and neurological surgery, urology, and proctology. In addition to routine undergraduate surgical teaching, clinical conferences and staff rounds are organized in each hospital and are well attended. On such occasions a number of patients with various lesions are shown and the diagnosis and treatment are discussed; or a definite subject is chosen and presented by a staff member, this being followed by a discussion. Original investigations are carried out in the laboratories, and facilities for pathological, clinical, and experimental research are provided.

There are two excellent clinics in Bogotá containing over 100 beds for the treatment of private patients. I was shown over them and was impressed with the facilities provided.

Most of our surgical work was carried out in the National Radium Institute, where every help was given by the director. Operations were also performed in the other teaching hospitals in the city.

The daily programme was a full one, the general plan being as follows. Surgical operations and anaesthetic demonstrations began at 8 a.m. and continued until 1 p.m. on four days a week. and until 11 a.m. on two days a week so that clinical meetings could be held. The staff were present at these meetings together with surgeons and doctors from other hospitals. The afternoons were devoted to discussions with staff members of hospitals, the examination of patients, or other work. Formal lectures were delivered daily at $6 \mathrm{p} . \mathrm{m}$. in the faculty of medicine of the National University. These lectures comprised both general and special subjects. Amongst the former were such topics as "The Contribution of Great Britain to World Surgery," "The London Blood Transfusion Service," ·etc. The special group included the surgical treatment of cancer in various sites, anaesthesia, and lectures on war surgery. This was the first occasion on which lectures on surgery in war had been given in the country.

The National Academy of Medicine is an important learned society where papers embodying original work are presented. We had the privilege of addressing this academy at a special session. I also addressed the Congress of Gynaecologists meeting under the auspices of the Bogotá Surgical Society at its San José Hospital. In addition an address was given to the National Colombian Society of Gastro-enterology.

\section{Medellin and Cartagena}

The teaching hospital in the former city is San Vincente, which is a large and busy institution. Surgical operations and anaesthetic demonstrations were carried out and lectures were delivered in the medical faculty of the University of Antioquia.

At a special meeting of the academic council of the University of Cartagena it was pleasing to hear the Director of Education and the Rector speak of the close bonds of affection which have linked Great Britain and Colombia together over a period of many years. We worked in the teaching hospital of Santa Clara and lectured in the faculty of medicine of the University.

\section{Malignant Disease in Colombia}

During my stay I saw a large number of patients with malignant disease and also studied statistical reports. As in Great Britain, many of the patients apply for treatment when the disease is far advanced. It is important to establish an anticancer campaign there, and I discussed this subject with the profession. They are very anxious to develop this work, and realize the importance, both for the lay population and for doctors, of an educational programme dealing with the early symptoms of this disease. It is hoped that this work will soon begin, and that it will result in patients being treated much earlier in the disease than at present.

Regarding the incidence of various types of malignant disease, I was struck with the number of cases there were of sarcoma and other tumours of bone. All types of case were seen, and from the records there did not appear to be any outstanding aetiological factor.

Carcinoma of the cervix uteri is one of the commonest forms of this disease, and the same applies to the breast. A fair number of cases of epithelioma of the vulva and vagina are seen, and certain parts of the alimentary canal appear to be affected more frequently than others, common sites being the mouth, oesophagus, and stomach. As in this country, every effort should be made to diagnose carcinoma of the stomach much earlier in its development than at present. There appear to be fewer cases of carcinoma of the colon and rectum than with us.

\section{General Impressions}

The vastness and the grandeur of the country leave an indelible impression upon the mind of the visitor, and distances are such that air travel is essential. The medical profession received us with great friendliness, and it is a pleasure to recall the kindnesses we received. The hospital arrangements are good, with units varying in size up to a bed complement of 1,200 . It is obvious that excellent surgical work is being done there, and the surgeons are keen and enthusiastic. There is a desire to progress and to learn new methods and techniques. It is hoped that facilities will be available for more of these keen young men to visit Great Britain and see the work here. Many Colombians wish to learn the English language, and in this and many other ways the British Council is doing excellent work.

It is a pleasure to thank the National University of Colombia for the invitation to undertake these travels, and also the University of Antioquia and the University of Cartagena for kindly asking us to visit them. The British Ambassador in Colombia gave us all possible help during our stay, and the Colombian Ambassador in London was most helpful in connexion with our visit. The medical profession in Colombia and many other friends showed us great kindness. The British Council made many arrangements for us, and its representatives in Colombia were most helpful throughout.

\section{HEALTH EDUCATION}

\section{National Conference in London}

Lord Woolton, president of the Central Council for Health Education, opened a two-day national conference at the Central Hall, Westminster, on November 8 . The conference was attended by 700 delegates from local health and education committees and voluntary organizations, with many medical officers of health and directors of education. An exhibition, opened by Sir Arthur Hobhouse, chairman of the County Councils Association, was held in association with the conference. This was much more than the usual miscellaneous display of pictorial material. It was planned in five sections, comprising the nature, needs, environment, and diseases of man, and the social and health services, each illustrated by means of models, films and film-strips, charts, posters, photographs, and booklets.

At the opening session Professor ANDREw TOPPING, of the University of Manchester, made a striking contribution in which he blamed the medical profession for the general lay attitude towards sickness-namely, the attitude that anatomy, physiology, and pathology were esoteric subjects, beyond the comprehension of the layman. Admittedly under present conditions it was difficult for the doctor to find time for frank discussion with inquiring patients instead of making an arbitrary diagnosis and giving a scribbled prescription, but eventually he hoped that a large part of the resources of the medical profession would be devoted to the things that really mattered-the education of the public, the prevention of disease, and the control of the basic factors that produced disease. 